\section{Seismic activity before earthquakes}

from Peter J. Smith

IT is now well known that many moderate and large earthquakes are immediately preceded by smaller foreshocks; that is, over periods ranging from weeks to hours before significant seismic events there is an increase in seismic activity. But what happens to the seismicity in the vicinity of an earthquake epicentre during the preceding months and years? Here opinions are more divided, with some studies concluding that the level of regional seismicity also generally increases over the longer time scale and others suggesting that earthquakes are frequently heralded by a period of relative quiescence.

Mogi (Bull. Earthquake Res. Inst., 47, 395; 1969), for example, concluded from a study of four great Japanese earthquakes that whereas the immediate epicentral area becomes relatively calm for some years prior to the main shock, activity in the surrounding regions increases markedly. He likened the pattern of seismicity to the shape of a ring doughnut centred on the epicentre. A somewhat similar pattern was also observed by Borovik et al. (Izv. Acad. Sci. USSR, Phys. Solid Earth, 2, 21; 1971) in a quite different tectonic setting. Borovik and his colleagues found that the area surrounding the 1959 Baykal (Soviet Union) earthquake was relatively quiet seismically for several years before the event and that the quiet area, or 'preparation region', enclosed the aftershock zone. During the $7 \frac{1}{2}$ years preceding the main earthquake, only two (smaller) earthquakes were observed within the preparation region whereas 20 were recorded in an outer region of comparable area. After examining the geological structure and seismicity of southern California, Allen et al. (Bull. Seismol. Soc. Amer., 55, 753; 1965) even went so far as to propose that areas of seismic quiescence may indicate the sites of future large earthquakes.

Fedotov et al. (in Earthquakes and the Deep Structure of the South Kurile Island Arc, Moscow, 1969) have taken precisely the opposite view, arguing from their study of the KamchatkaKurile-Japan seismic zones that impending great earthquakes are heralded by an increase in seismic activity beginning 5-20 years before. In this they are supported by Sadovsky et al. (Tectonophysics, 14, 295; 1972) who suggested on the basis of Asian studies that an increase in seismic activity over a 5-10 year period indicates 'a forthcoming strong earthquake. Suyehiro and Sekiya (Tectonophysics, 14, 219;
1972) also found that the seismicity in the vicinity of the great Kanto earthquake of 1923 was significantly greater during the few years before the shock than over the period 1926-1972. And finally, Tocher (in San Francisco Earthquakes of March 1957, California Division of Mines and Geology, Spec. Rep. 57, 1959) concluded that for several decades preceding the Hayward earthquake of 1868 and the San Francisco earthquake of 1906 moderate earthquakes probably occurred at a greater frequency than they do on average over the longer term. He thus interpreted increasing regional seismicity as a symptom of a strain buildup which could subsequently lead to a major shock.

So which side is right? Or is the conflict more apparent than real, either because different earthquakes are associated with genuinely different precursory phenomena or because experimental and analytical techniques have hitherto been imperfect? In an attempt to resolve the matter, Kelleher and Savino (J. Geophys, Res., 80, 260; 1975) have now carried out an extensive study of the patterns of seismic activity preceding large strike-slip and thrust-type earthquakes which have occurred along the northern, northwestern and eastern margins of the Pacific. The events include the San Francisco earthquake of 1906, the Kamchatka event of 1952, the Chile shock of 1960 , the great Alaska earthquake of 1964 and several others, most of which had rupture zones extending hundreds of kilometres. In each case the foci of all shallow $(<100 \mathrm{~km})$ events preceding the main shocks were relocated, in some cases for precursory intervals of up to 45 years.

The observed patterns of seismicity preceding large earthquakes were found to correlate with the configurations of the shocks' rupture zones and with the positions of the main event epicentres within the zones. Specifically, extensive parts of the rupture zones were relatively aseismic until the times of the main shocks, and the low levels of seismicity applied to events at least several magnitudes smaller than the main shocks and probably to events many magnitudes smaller. On the face of it, this would seem to support those arguing for precursory quiescence; in practice, the detailed picture looks rather different. In most of the earthquakes examined by Kelleher and Savino rupture began in an area of moderate seismic activity, propagated up to hundreds of kilometres into adjacent quiet regions, and in many cases ended in areas with marked prior seismicity. Thus prior seismic activity often occurred near the epicentres of the main events and near the edges of the rupture zones but not throughout the main bodies of the zones.

These general principles are well illustrated by the Kamchatka earthquake of 6 November 1952. During the earthquake, rupture propagated from the focus towards the south-west, parallel to the strike of the thrust plane and throughout an elongated zone 400$500 \mathrm{~km}$ long and 100-200 km wide. For 30 years before the earthquake, most of the rupture zone was relatively quiet seismically; but throughout this period there was a clustering of activity around the position of the subsequent epicentre at the north-east of the rupture zone and around the opposite (south-western) end of the zone. The bulk of the rupture zone only became seismically active with the aftershocks of the main earthquake.

There is some indication from the Kamchatka and other large earthquakes that, where prior activity does occur (especially in the epicentral regions), its level increases as the main shock approaches. On the one hand, there is no suggestion that precursory seismic activity appears in the gaps where none occurred before. Gaps in seismicity for great earthquakes along major plate boundaries seem to be gaps for smaller magnitude activity also; and these gaps remain until and unless they become aftershock zones. Unfortunately, the available data are insufficient to enable temporal variations to be determined in any great detail. Thus it is not yet possible to say whether a seismic gap becomes quiescent as part of a definite process leading to a large earthquake or whether, once the aftershocks of a large event have died away, the gap remains quiescent until the next large shock. At present there are data to support either behaviour but not enough to decide which predominates. What the new study by Kelleher and Savino has made clear, however, is that the spatial distribution of seismicity is critical in any attempt to describe temporal variations. It is not enough to say that a particular earthquake was preceded by relative quiescence or a regional increase in the level of seismic activity. The precise points at which these phenomena do or do not take place must be clearly determined.

\section{Turnover of motor endplate}

from Angela Vincent

THE transmission of impulses at the neuromuscular junction is achieved by the release of acetylcholine from the nerve ending. Acetylcholine interacts with receptors on the endplate of the muscle and causes a change in sodium and potassium permeability which 